\title{
Elvira Savi Federici (1920-2013)
}

Elvira Savi, la Maestra, nos ha dejado. Según ella misma contaba, estudió piano desde su más tierna infancia en el Conservatorio Nacional de Música de la Universidad de Chile con don Federico Duncker, Alberto Spikin y Rosita Renard. Se tituló muy joven para iniciar su carrera como solista y como acompañante. Llegó a trabajar al Conservatorio en la entonces Facultad de Bellas Artes a los 15 años, como pianista acompañante del curso de la profesora Ema Ortiz. Con los años se convirtió en una autoridad indiscutida en materia de música de cámara y acompañamiento, especialmente de canto.

Somos muchas generaciones de músicos los que hemos tenido el inmenso privilegio de haber sido sus alumnos. Personalmente tuve la suerte de tenerla como pianista acompañante del curso de canto de mi maestra Lila Cerda desde el primer día que entré al Conservatorio.

Como solista, Elvira abordó el repertorio más amplio que se pueda imaginar, desde conciertos de Bach para piano y orquesta hasta el estreno en Chile de Los pájaros de Olivier Messiaen, obra que me tocó escuchar con verdadera devoción en mi primera juventud, mientras cumplía el delicado trabajo de darle vuelta las páginas de la partitura en el concierto con la Orquesta Sinfónica de Chile bajo la dirección de Víctor Tevah.

Elvira fue un verdadero faro para nosotros y para mí personalmente fue un permanente ejemplo de seriedad, corrección, de trato digno, cariñoso pero firme, que nunca dudaba en decir la verdad a todos y especialmente a sus estudiantes. En ocasiones llegó a ser algo dura, pero luego nos dábamos cuenta de que era su cariño el que hablaba, cariño de madre hacia sus hijos.

Su capacidad musical era asombrosa, su talento algo pocas veces visto, sin embargo era tremendamente rigurosa en el estudio, perfeccionista, dedicada ciento por ciento a la obra que estaba trabajando en ese momento.

Estudiar con ella una obra era algo maravilloso, pues siempre descubría detalles de interpretación que hacían que cada obra se convirtiera en algo vivo.

Me tocó muchísimas veces sumergirnos juntas en obras chilenas no estrenadas o muy poco interpretadas o en obras contemporáneas con grupos de cámara. Esto se convertía junto a ella en una aventura fascinante, llena de descubrimientos, de sugerencias, de consejos llenos de sabiduría, con una sorprendente imaginación y creatividad.

Nos tocó hacer innumerables giras de concierto. Siempre su buen humor y jovialidad ponían la nota alegre, incluso cuando se producían los típicos problemas de una gira, los atrasos, los viajes agotadores, las salas mal acondicionadas, los pianos de calidad regular, los hoteles llenos de fallas, en fin, lo que todos conocemos, pero ella nunca se quejaba, todo lo tomaba por su mejor lado y el éxito del concierto junto al aplauso del público eran su mejor panacea.

Viajamos por todo Chile, tuvimos sabrosísimas aventuras, conocimos gente increíble, viajamos también a la Argentina, a Perú, a Ecuador. Llevamos siempre en nuestros programas una gran parte dedicada a obras de compositores chilenos, labor que ella siempre desarrolló en forma excelente y tesonera.

Elvirita era una mujer fuerte, valiente, amante de su familia, preocupada como leona con sus cachorros de sus hijos, compañera fiel del inolvidable Enrique (Anex dit Chenaud), su marido, quien con su inconmovible flema suiza venía a buscarla al Conservatorio para ir juntos a tomar té al Café Santos o al Villarreal.

Nos recibía en su casa de la calle Garibaldi en Santiago para ensayar nuestros conciertos. Allí era de admirar su lado de mujer de su casa, pues todo relucía de limpio y ordenado. Ella se levantaba a las 5 de la mañana todos los días para dejar su casa reluciente antes de irse al Conservatorio.

Recuerdo cuando estábamos en clase y llegaba a preguntar por ella su hijo Pancho (Q.E.P.D.). Nosotras, alumnas jóvenes y románticas, suspirábamos y corríamos a divisarlo para sonar con sus ojos verdes y su cabeza de arcángel. Elvirita adoraba a sus hijos y la trágica muerte de Pancho fue para ella un golpe muy duro. Pero su valor era algo ejemplar. Cuando falleció su compañero de la vida, Enrique, Elvira, a los pocos días, debía partir a cumplir su compromiso como pianista del Concurso Internacional de Interpretación musical Luis Sigall en Viña del Mar. Todos pensamos que renunciaría, pero ella, haciendo gala de una fortaleza increíble, cumplió con su trabajo en forma excelente y ejemplar, como siempre. Fue la pianista oficial del Concurso Sigall durante más de treinta años y los solistas extranjeros que venían a hacer recitales a Chile pedían con insistencia que su acompañante fuera Elvira Savi, pues su fama trascendía las fronteras del país. 
Su hija Silvia fue su permanente compañera y sus nietos eran los preferidos de su enorme y generoso corazón.

Para nuestra Facultad de Artes y nuestra Universidad de Chile, Elvira, profesora emérita, fue y seguirá siendo un ejemplo para los que tuvimos la suerte de conocerla bien y trabajar años junto a ella y también para las generaciones futuras de músicos. Los compositores chilenos le deben un eterno reconocimiento, pues la mayor parte de su trabajo tesonero estuvo enfocado en la difusión de las obras nacionales para piano, canto y piano o música de cámara. Llegó a estrenar y grabar una cantidad enorme de obras nacionales para el conocimiento de nuestra música en el mejor y más excelente nivel de interpretación que se pueda pedir.

Para Chile, Elvira Savi Federici ha sido una gloria, y con toda justicia el Estado de Chile le otorgó en el año 1998 el Premio Nacional de Artes Musicales, máximo galardón que el país entrega a sus hijos por servicios distinguidos a la Patria.

Carmen Luisa Letelier Valdés Profesora Titular Universidad de Chile Premio Nacional de Arte 2010 mileval@vtr.net 